\title{
Role of Urinary Neutrophil Gelatinase-associated Lipocalin as a Biomarker of Acute Kidney Injury in Patients with Circulatory Shock
}

\author{
Radhey Shyam, Munna Lal Patel', Rekha Sachan², Satish Kumar³, Durgesh Kumar Pushkar ${ }^{3}$ \\ Department of Anaesthesiology, Intensive Care Unit, King George Medical University, 'Department of Medicine, Nephrology Unit, King George Medical University, \\ Departments of ${ }^{2} \mathrm{Obstetrics}$ and Gynaecology and ${ }^{3}$ Medicine, King George Medical University, Lucknow, Uttar Pradesh, India
}

\section{Abstract}

Background: The early prediction of acute kidney injury (AKI) by the current clinical and laboratory methods remains inadequate. Neutrophil gelatinase-associated lipocalin (NGAL) has emerged as a promising noninvasive biomarker of kidney injury in shock. The aim of this study was to assess the ability of urinary NGAL (UNGAL) to predict AKI in adult Intensive Care Unit (ICU) patients. Materials and Methods: We prospectively studied 70 patients with circulatory shock admitted to the ICU over a period of 1 year. uNGAL was analyzed at ICU admission and after $24 \mathrm{~h}$. Risk, injury, failure, loss, and end-stage kidney criteria were calculated at admission and for consecutive 4 days. The primary outcome was AKI defined as an increase in creatinine of at least $50 \%$ from baseline or a reduction in urine output to $<0.5 \mathrm{ml} /$ $\mathrm{kg} / \mathrm{h}$ for $6 \mathrm{~h}$. Results: uNGAL was a good diagnostic marker for AKI development; at day 1, the cutoff value $48.54 \mathrm{ng} / \mathrm{mL}$ had a sensitivity and specificity of 79.49 and 73.14 , respectively, and the area under the curve (AUC) of 0.82 (95\% confidence interval [CI], 0.75-0.87) for predicting AKI. At day 2, the cutoff value $190.92 \mathrm{ng} / \mathrm{mL}$ had a sensitivity and specificity of 90.0 and 64.66, respectively, and the AUC of 0.76 (95\% CI, 0.70-0.88) for predicting AKI. Conclusion: uNGAL could be a good early predictor biomarker of AKI following circulatory shock.

Keywords: Acute kidney injury, biomarker, circulatory shock, sensitivity and specificity, urinary neutrophil gelatinase-associated lipocalin

\section{INTRODUCTION}

Shock is the clinical expression of circulatory failure that results in inadequate tissue perfusion. About one-third of all critically ill patients manifest with shock. Acute kidney injury (AKI) is a common occurrence in these patients, affecting $25 \%$ of all Intensive Care Unit (ICU) admissions. Circulatory shock is thought to be the most common contributing factor to AKI in these patients and is associated with high mortality rates of $40 \%-50 \% \cdot{ }^{[1,2]}$ Mortality rates from AKI in circulatory shock have not declined significantly over the years, mainly because of late diagnosis and paucity of early sensitive and specific biomarkers for AKI. ${ }^{[3]}$

AKI is commonly diagnosed by rising serum creatinine; however, this results in late diagnosis and is insensitive as the rise may not be detected early in subtle injuries. Serum creatinine requires several hours to days to accumulate. It increases in serum only after $50 \%$ or more of renal function is

\begin{tabular}{|l|l|}
\hline \multicolumn{3}{|c|}{ Access this article online } \\
\hline Quick Response Code: & Website: \\
\hline & www.ijccm.org \\
\hline & \\
\hline
\end{tabular}

lost and its concentration is affected by multiple confounding factors. Effective preventive and therapeutic measures are available, but diagnosis of AKI in shock is frequently delayed due to lack of an early predictive biomarker. An early detection of patients with kidney injury would provide an opportunity to treat and prevent the extension of kidney injury before the serum creatinine rises and renal injury progresses. ${ }^{[4]}$

Recent studies have proposed many biomarkers for the early detection of AKI, which may facilitate earlier diagnosis and proper management, resulting in fewer complications and improved outcomes. ${ }^{[5,6]}$ One among these promising

Address for correspondence: Dr. Munna Lal Patel, Department of Medicine, King George Medical University, C-28, Sec-J Aliganj, Lucknow - 226 024, Uttar Pradesh, India. E-mail: patel.ml66@gmail.com

This is an open access article distributed under the terms of the Creative Commons Attribution-NonCommercial-ShareAlike 3.0 License, which allows others to remix, tweak, and build upon the work non-commercially, as long as the author is credited and the new creations are licensed under the identical terms.

For reprints contact: reprints@medknow.com

How to cite this article: Shyam R, Patel ML, Sachan R, Kumar S, Pushkar DK. Role of urinary neutrophil gelatinase-associated lipocalin as a biomarker of acute kidney injury in patients with circulatory shock. Indian J Crit Care Med 2017;21:740-5. 
biomarkers, neutrophil gelatinase-associated lipocalin (NGAL) is a $25 \mathrm{kDa}$ member of the lipocalin family, first discovered as a protein in granules of the human neutrophils. It is normally expressed at very low levels in several human tissues, including the kidneys, lungs, stomach, and colon. ${ }^{[7,8]}$ After ischemic injury, NGAL levels in kidney tissue rise by 10 -fold within $3 \mathrm{~h}$. This rise appears to be sustained, being evident for several days following the initial insult. This pattern of early rise and persistence makes NGAL a highly sensitive marker for diagnosing AKI.

Very few studies have addressed the role of urinary NGAL (UNGAL) as a biomarker of AKI in circulatory shock. The aim of this study was to investigate the pattern of uNGAL level as an early biomarker of AKI in patients with circulatory shock.

\section{Materials and Methods}

This was a prospective cohort study carried out in the ICU of the Department of Medicine, King George Medical University, Lucknow, Uttar Pradesh (UP), India, over a period of 1 year. The reporting of this study follows the Strengthening the Reporting of Observational Studies in Epidemiology guideline. ${ }^{[9]}$ After informed written consent and approval from the Institutional Ethics Committee, the patients were enrolled in the study. This study was conducted on 70 patients admitted to ICU in the Department of Medicine, King George Medical University, Lucknow, UP, India, from August 2014 to July 2015 with circulatory shock. All patients were enrolled in the study and followed up, during their hospital stay. All subjects were enrolled in the study within $6 \mathrm{~h}$ from the diagnosis of circulatory shock with normal kidney functions and followed up consecutively for 4 days during their stay in ICU.

\section{Inclusion criteria}

Patients admitted in ICU with low blood pressure and diagnosed on the basis of the Empiric Criteria of Circulatory Shock, which requires at least four criteria out of altered mental status (AMS), heart rate $>100$ beat $/ \mathrm{min}$, respiratory rate $>22 / \mathrm{min}$, or $\mathrm{PaCO} 2<32 \mathrm{mmHg}$, arterial hypotension (systolic blood pressure $<90 \mathrm{mmHg}$ or mean arterial blood pressure $\leq 70 \mathrm{mmHg}$ ) for $>20 \mathrm{~min}$ duration, urine output $<0.5 \mathrm{~mL} / \mathrm{kg} / \mathrm{h}$, or arterial base deficit $<-5 \mathrm{mEq} / \mathrm{L}$ were included.

\section{Exclusion criteria}

Patients of circulatory shock with preexisting renal insufficiency (baseline serum creatinine $>2 \mathrm{mg} / \mathrm{dl}$ ), recent use of nephrotoxic drugs, urinary tract infection (presence of $>50$ pus cells/HPF), known cases of polycystic kidney, lupus nephritis, or IgA nephropathy, known cases of malignancy or postrenal transplant subjects were excluded.

AKI is a common occurrence in ICU patients, affecting approximately $25 \%$ of all admissions. After enrollment, all patients were subjected to full clinical evaluation including medical history and clinical examination, routine laboratory investigations including blood urea and serum creatinine, arterial blood gases, complete blood count, and urine analysis and abdominal ultrasonography to rule out any prior kidney disease. The Modification of Diet in Renal Disease formula was used to calculate the estimated glomerular filtration rate (eGFR). AKI staging was done using the AKI network criteria [Table 1].

All patients were subjected to full clinical evaluation every 2 hourly, and measurements of the routine hematology and other laboratory investigations including blood urea, serum creatinine, uric acid, liver function tests, serum electrolytes, serum protein, albumin, and eGFR were done at days 2, 3, and 4. Estimation of uNGAL using Human ELISA Kit (Epitope Diagnostics, Inc., San Diego, USA) was done at day 1 (within the first $6 \mathrm{~h}$ of the patient enrollment) and after $24 \mathrm{~h}$ on day 2 as per the manufacturer's protocol.

\section{Follow-up and endpoints}

Baseline renal function tests for all patients were recorded at the time of enrollment. All of the patients were followed till hospital stay. The primary follow-up endpoint was development of AKI in first 4 days. Secondary follow-up endpoint was number of subject expired during this period.

\section{Statistical analysis}

The continuous data were summarized using descriptive statistics (mean \pm standard deviation). Statistical differences between the mean values were compared using Student's $t$-test. A difference between the two values was considered to be significant if the $P<0.05$. The association between two or more categorical variables was tested by Chi-square statistics using appropriate correction. Before carrying out any test on continuous data, the normalcy of data was tested. The two-sample $t$-test was used to see the difference between the mean of two different groups if data were normally distributed. If data were not found to be normally distributed, the Mann-Whitney test was used to test the level of significance between two values. One-way analysis of variance (ANOVA) was used to test the difference among two groups in case of normally distributed data. Receiver operating characteristics curve was used to test the efficiency of UNGAL in predicting AKI. All calculations were done using STATA IC13 (Texas) and MedCalc Version 17.5.5 software (Belgium).

\section{RESULTS}

Clinical and biochemistry data of both groups were comparable. Mean age in case group was $45.69 \pm 14.63$ years in comparison

\begin{tabular}{lll}
\hline Table & : & Acute kidney injury network criteria \\
\hline Stage & Serum creatinine criteria & $\begin{array}{l}\text { Urine output } \\
\text { criteria }\end{array}$ \\
\hline 1 & $\begin{array}{l}\uparrow \text { to } \geq 1.5 \times \text { base line or } \uparrow 0.3 \mathrm{mg} / \mathrm{dl} \text { from } \\
\text { base line }\end{array}$ & $<0.5 \mathrm{ml} / \mathrm{kg} / \mathrm{h} \geq 6 \mathrm{~h}$ \\
& $\uparrow$ to $\geq 2 \times$ base line & $<0.5 \mathrm{ml} / \mathrm{kg} / \mathrm{h} \geq 12 \mathrm{~h}$ \\
3 & $\uparrow$ to $\geq 3 \times$ from base line or $4 \mathrm{mg} / \mathrm{dl}$ with & $<0.30 \mathrm{ml} / \mathrm{kg} / \mathrm{h}$ \\
& $\begin{array}{l}\text { acute } \uparrow \geq 0.5 \mathrm{mg} / \mathrm{dl} \text { or initiate of } \mathrm{RRT} \\
\text { irrespective of age at the time of initiation }\end{array}$ & \\
\hline
\end{tabular}

Only one criterion (serum creatinine or urine output) should be fulfilled to qualify for a stage. RRT: Renal replacement therapy; $\uparrow:$ Increased; X: Times 
to control $40.56 \pm 14.8$ years, $44.4 \%$ diabetics in case group and $48 \%$ in control group, $97.7 \%$ versus $88 \%$ of patients with AMS, so there was a significant decline in the mean values of AMS $(P<0.01)$. Distribution of cases due to circulatory shock in case group was hypovolemic $22(48.8 \%)$, cardiogenic $5(11.1 \%)$, septic $12(26.7 \%)$, and distributive $6(13.3 \%)$, while in control group, circulatory shock due to different etiology was hypovolemic $10(40 \%)$, cardiogenic 7 (28\%), septic $6(24 \%)$, and distributive $2(8 \%)(P>0.05)$ [Table 2].

Urine output was slightly lower in cases in comparison to control $(P=0.82)$. Mean arterial blood pressure was toward lower side in cases with comparison to control $(P<0.01)$. The base deficit showed significantly lower values in the patients group $-10.6 \pm 9$ compared to the controls $-4.6 \pm 7(P<0.01)$. Both the ICU stay days and number of deaths were significantly higher in the patient group rather than the controls [Table 1].

Compared to the controls, renal function tests of the patients showed significantly higher values at all days, except at day 1 which showed comparable values to the controls [Figure 1]. The only exception was UNGAL which showed significantly higher values at day 1 and day 2 in the patients' group compared to the controls [Figure 1].

During hospital stay on day 1, in patients group, 20 (45\%) develops AKI in comparison to control group $7(28 \%)$. Number of AKI patients increases on day 2, $41(91 \%)$ and day 3, $40(88.8 \%)$ in patients group, respectively. However, there is no increase in AKI patients in control group. There is no further increase in AKI patients on day 4. This pattern of increase shows that AKI develops 48-72 $\mathrm{h}$ later from the development of shock [Table 3]. Development of AKI further leads to changes in urine output. Effect of urine output on uNGAL using one-way ANOVA test shows increase level of uNGAL at day 1 was $48.3 \pm 34.4$ and on day 2 was $190 \pm 30.4(\mathrm{ng} / \mathrm{ml})$. High value of uNGAL at day 1 and day 2 without increase in serum creatinine reflects further development of AKI on $3^{\text {rd }}$ and $4^{\text {th }}$ day [Table 4].

ICU stay in days was comparable between the patients and the controls; the survivors stayed for $12.18 \pm 2.52$ days compared to $13.60 \pm 2.27$ days for the controls $(P<0.001)$, and those who died stayed for $5 \pm 2.5(2-15)$ days compared to $7.8 \pm 5.4(2-13)$ days for the controls $(P<0.001)$. uNGAL values were toward increasing trends at day 1 and day 2 in both groups. Compared to the controls, significantly higher mortality rate could be detected in the patients group. Thirty-six patients ( $80 \%)$ died compared to $6(24 \%)$ controls $(P<0.001)$. Nine patients (20\%) survived compared to $19(76 \%)$ of controls $(P<0.001)$ [Table 2].

\section{Prediction of acute kidney injury using urinary neutrophil gelatinase-associated lipocalin}

The best cutoff value was $48.54 \mathrm{ng} / \mathrm{mL}$ and $190.92 \mathrm{ng} / \mathrm{mL}$ at days 1 and 2, respectively, to determine AKI. At day1, uNGAL at cutoff value of $48.54 \mathrm{ng} / \mathrm{mL}$ had a sensitivity and specificity of 79.49 and 73.14 , respectively, and the area under the curve (AUC) of 0.82 (95\% confidence interval [CI],

\begin{tabular}{|c|c|c|c|}
\hline \multicolumn{4}{|c|}{$\begin{array}{l}\text { Table 2: Clinical and laboratory parameter of both group } \\
\text { at day } 1\end{array}$} \\
\hline Parameter & Cases (45) & $\begin{array}{c}\text { Control } \\
(25)\end{array}$ & $\begin{array}{l}\text { Significance } \\
(P)\end{array}$ \\
\hline Age (years) & $45.69 \pm 14.63$ & $40.56 \pm 14.8$ & 0.17 \\
\hline AMS (\%) & $44(97.7)$ & $22(88)$ & $<0.01$ \\
\hline SBP (after fluid therapy) & $89.44 \pm 11.11$ & $111.20 \pm 7.26$ & $<0.001$ \\
\hline DBP (after fluid therapy) & $58.60 \pm 9.49$ & $75.76 \pm 4.48$ & $<0.001$ \\
\hline $\mathrm{Hb}(\mathrm{g} / \mathrm{dl})$ & $7.71 \pm 1.24$ & $9.13 \pm 2.86$ & $<0.01$ \\
\hline Mean arterial BP (mmHg) & $36.8 \pm 22.6$ & $40.6 \pm 16.8$ & $<0.01$ \\
\hline Urine output $(\mathrm{ml} / \mathrm{kg} / \mathrm{h})$ & $0.76 \pm 0.48$ & $0.86 \pm 0.52$ & 0.82 \\
\hline Diabetes mellitus (\%) & $20(44.4)$ & $12(48)$ & $>0.05$ \\
\hline \multicolumn{4}{|l|}{ Circulatory shock (\%) } \\
\hline Hypovolemic & $22(48.8)$ & $10(40)$ & $>0.05$ \\
\hline Cardiogenic & $5(11.1)$ & $7(28)$ & $>0.05$ \\
\hline Septic & $12(26.7)$ & $6(24)$ & $>0.05$ \\
\hline Distributive & $6(13.3)$ & $2(8)$ & $>0.05$ \\
\hline Base deficit $(\mathrm{mEq} / \mathrm{L})$ & $\begin{array}{c}-10.6 \pm 9 \\
(-28.8-8.6)\end{array}$ & $\begin{array}{c}-4.6 \pm 7 \\
(-18.8-5.6)\end{array}$ & $<0.05$ \\
\hline ICU stay (days) & $12.18 \pm 2.52$ & $13.60 \pm 2.27$ & $<0.05$ \\
\hline ICU mortality (\%) & $36(80.0)$ & $6(24.0)$ & $<0.001$ \\
\hline
\end{tabular}

\begin{tabular}{lccc}
\hline \multicolumn{4}{l}{ Table 3: Acute kidney injury score on all days } \\
\hline & Patient (\%) & Control (\%) & $\boldsymbol{P}$ \\
\hline Day 1 & $20(45)$ & $7(28)$ & $\mathrm{NS}$ \\
Day 2 & $41(91)$ & $5(20)$ & $<0.001$ \\
Day 3 & $40(88.8)$ & $2(8)$ & $<0.001$ \\
Day 4 & $22(48.8)$ & $1(5)$ & $<0.001$ \\
\hline
\end{tabular}

NS: Not significant

\begin{tabular}{|c|c|c|}
\hline Parameter & Patient & Control \\
\hline uNGAL (ng/ml) day 1 & $48.3 \pm 34.4(34-134)$ & $14.5 \pm 9.4(4.2-24)$ \\
\hline uNGAL (ng/ml) day 2 & $190 \pm 30.4(25-148)$ & $20.5 \pm 25.4(3-56)$ \\
\hline$P$ & $<0.05$ & $>0.05$ \\
\hline
\end{tabular}

uNGAL: Urinary neutrophil gelatinase-associated lipocalin

0.75-0.87) for predicting AKI. At day 2, uNGAL at cutoff value of $190.92 \mathrm{ng} / \mathrm{mL}$ had a sensitivity and specificity of 90.0 and 64.66 , respectively, and the AUC of 0.76 (95\% CI, 0.70-0.88) for predicting AKI [Table 5 and Figure 2].

\section{Prediction of renal replacement therapy using urinary} neutrophil gelatinase-associated lipocalin

At day 1, the cutoff value $45.54 \mathrm{ng} / \mathrm{mL}$ had a sensitivity and specificity of 79.49 and 74.14 , respectively, and the AUC of 0.82 (95\% CI, 0.75-0.87) for predicting the need of hemodialysis. At day 2, the cutoff value $200.99 \mathrm{ng} / \mathrm{mL}$ had a sensitivity and specificity of 90.0 and 64.66, respectively, and the AUC of $0.82(95 \% \mathrm{CI}, 0.75-0.88)$ for predicting the need of hemodialysis [Table 6 and Figure 3]. 


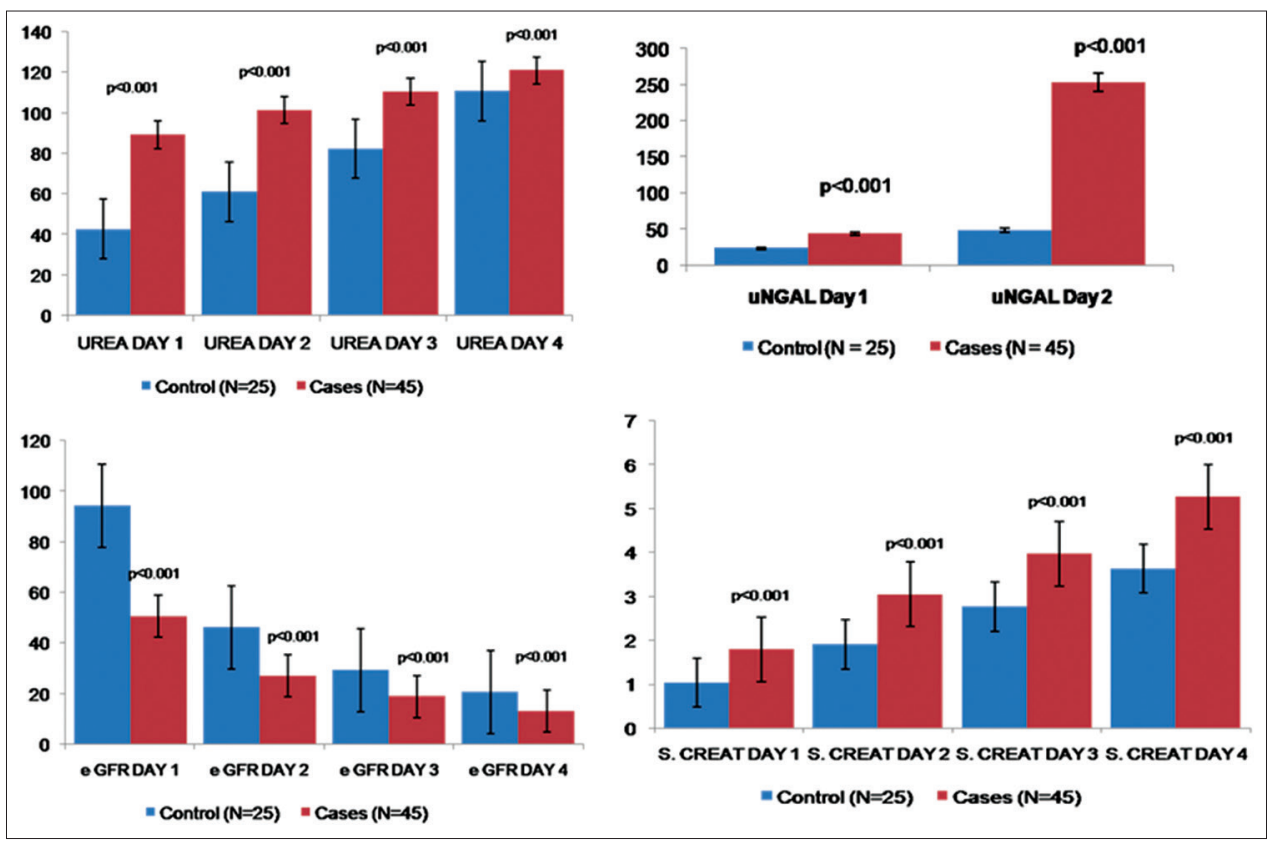

Figure 1: Urinary neutrophil gelatinase-associated lipocalin and renal parameters in both groups. Significant increase in the mean values of urea, urinary neutrophil gelatinase-associated lipocalin, and serum creatinine were observed in cases as compared to control subjects. For estimated glomerular filtration rate, significant decline in the mean values were observed in cases as compared to control subjects

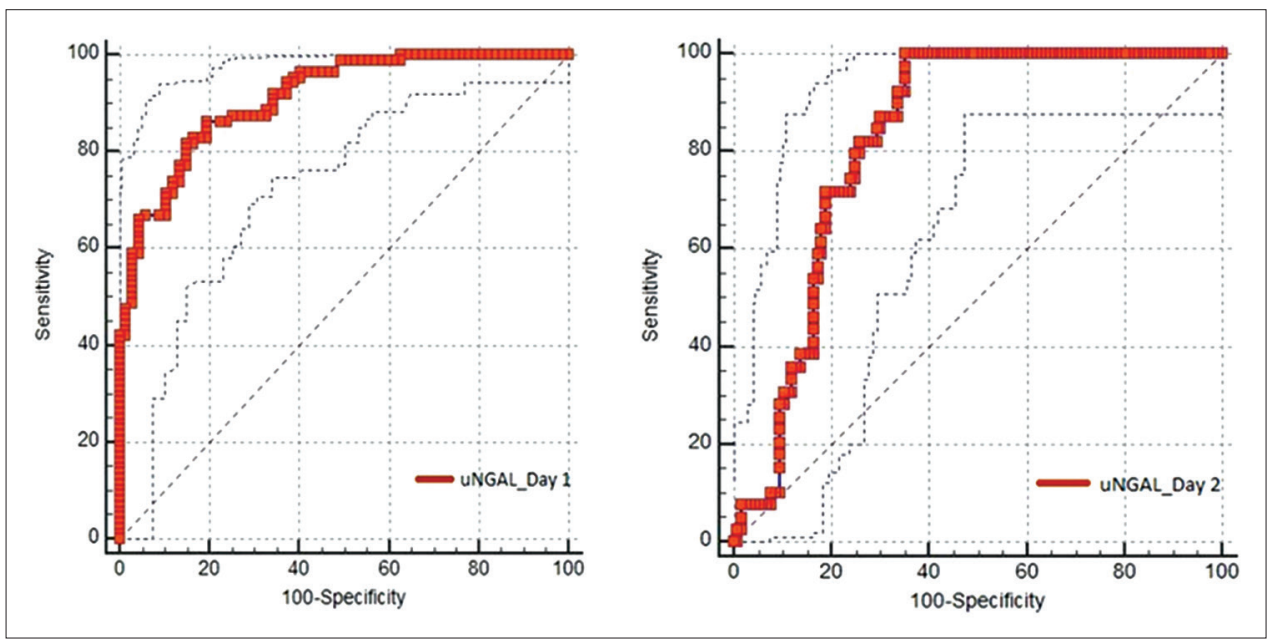

Figure 2: Prediction of acute kidney injury using urinary neutrophil gelatinase-associated lipocalin at day 1 and day 2

Table 5: Prediction of acute kidney injury using urinary neutrophil gelatinase-associated lipocalin at day 1 and day 2

\begin{tabular}{lcc}
\hline Parameter & uNGAL (day 1) & UNGAL (day 2) \\
\hline Sensitivity & 79.49 & 90.0 \\
Specificity & 73.14 & 64.66 \\
AUC & $0.82(0.75-0.87)$ & $0.76(0.70-0.88)$ \\
Best cutoff value & 48.54 & 190.92 \\
\hline At day 1, the cutoff value $48.54 \mathrm{ng} / \mathrm{mL}$ had a sensitivity and specificity of \\
79.49 and 73.14, respectively, and the area under curve of $0.82(95 \% \mathrm{CI}:$ \\
0.75-0.87) for predicting AKI. At day 2, the cutoff value $190.92 \mathrm{ng} / \mathrm{mL}$ \\
had a sensitivity and specificity of 90.0 and 64.66 , respectively, and the \\
AUC of 0.76 (95\% CI: 0.70-0.88) for predicting AKI. AUC: Area under \\
the curve; uNGAL: Urinary neutrophil gelatinase-associated lipocalin; \\
CI: Confidence interval; AKI: Acute kidney injury
\end{tabular}

\section{Discussion}

Recent advances in the detection of early ischemic injury to renal tubule cells have led to the discovery of newer novel biomarkers for AKI. These novel biomarkers can help in early diagnosis of renal injury and therefore improves final outcomes in patients of AKI. ${ }^{[5,10]}$ An ideal urinary biomarker for AKI should be sensitive and specific. It should be capable of reflecting time-dependent changes in the severity of kidney injury. Along with these criteria, it should also be easily measurable, cheap, and easy to interpret. However, no single urinary biomarker has been found to fulfill all these criteria. ${ }^{[11]}$

The neutrophil gelatinase-associated lipocalin is probably the most promising biomarker for AKI in ICU settings where 


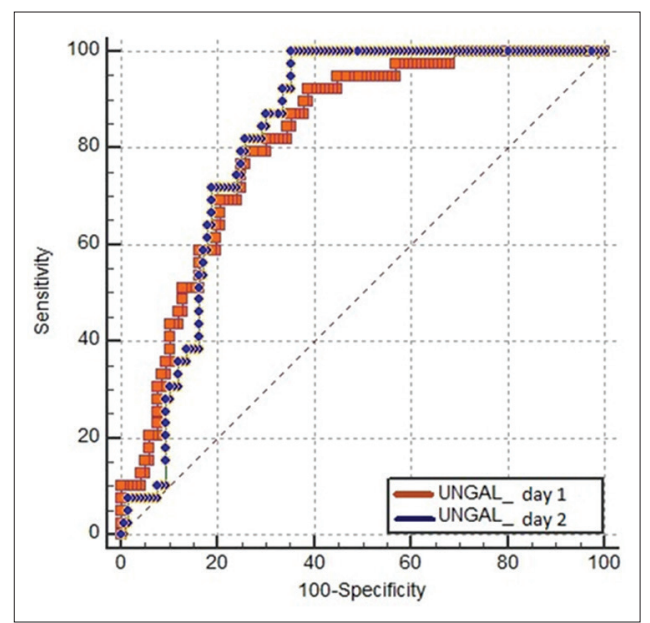

Figure 3: Prediction of need for dialysis using urinary neutrophil gelatinase-associated lipocalin at day 1 and day 2

\begin{tabular}{|c|c|c|}
\hline Parameter & uNGAL (day 1) & uNGAL (day 2) \\
\hline Sensitivity & 79.49 & 90.0 \\
\hline Specificity & 74.14 & 64.66 \\
\hline AUC & $0.82(0.75-0.87)$ & $0.82(0.75-0.88)$ \\
\hline Best cut-off value & 45.54 & 200.99 \\
\hline \multicolumn{3}{|c|}{$\begin{array}{l}\text { At day 1, the cut-off value } 45.54 \mathrm{ng} / \mathrm{mL} \text { had a sensitivity and specificity } \\
\text { of } 79.49 \text { and } 74.14 \text { respectively and the AUC of } 0.82 \text { ( } 95 \% \text { CI: } 0.75-0.87) \\
\text { for predicting the need of hemodialysis. At day } 2 \text {, the cut-off value } \\
200.99 \mathrm{ng} / \mathrm{mL} \text { had a sensitivity and specificity of } 90.0 \text { and } 64.66 \\
\text { respectively and the AUC of } 0.82 \text { ( } 95 \% \text { CI: } 0.75-0.88 \text { ) for predicting } \\
\text { the need of hemodialysis. AUC: Area under the curve; CI: Confidence } \\
\text { interval; uNGAL: Urinary neutrophil gelatinase-associated lipocalin }\end{array}$} \\
\hline
\end{tabular}

its rise can precede that of serum creatinine by several hours to days. ${ }^{[10]}$ It is highly upregulated in the setting of renal inflammation and injury in both blood and urine. ${ }^{[12]}$ However, uNGAL has been found to be more sensitive and specific than plasma NGAL. ${ }^{[13]}$

A cross-sectional study done by Mori et al. in ICU patients with AKI found a $>10$-fold increase in plasma NGAL and a $>100$-fold increase in uNGAL compared to their control group. ${ }^{[14]}$ In our study, significantly increased values of uNGAL at days 1 and 2 were detected in the patients' group, with reduction of the urine output $(P<0.05$ and $P<0.001)$. AKI score showed also a good correlation with uNGAL only at day 2; otherwise, no correlation could be detected between uNGAL and the other kidney function tests including blood urea, serum creatinine, and GFR.

There are variable kidney responses to fluid and vasopressors therapy in circulatory shock to initial resuscitation management strategy. In another study done by Mori et al., they found that both plasma NGAL and UNGAL correlated strongly with serum creatinine levels. ${ }^{[14]}$ These findings were in disagreement with our study that this study was conducted on patients with already established renal failure, while in our study, the patients with circulatory shock were in early phase of AKI.

In a study of Cruz et al. on 307 adult patients admitted to ICU, approximately 40\% develops AKI during hospital stay. Plasma NGAL was a good diagnostic marker for AKI development within next 48 h (AUC 0.78, 95\% CI $0.65-0.90) \cdot{ }^{[15]}$ In a prospective study of Constantin et al. on 88 adult patients admitted to ICU, plasma NGAL predicts AKI with sensitivity and specificity of $82 \%$ and $97 \%$ with AUC 0.92 (0.652-0.972). ${ }^{[16]}$ Another study done by Fouda et al. on 45 patients with circulatory shock showed that uNGAL at day 1 and day 2 showed sensitivity and specificity of $62 \%$ and $69 \%$ and $75 \%$ and $80 \%$, respectively, for the prediction of AKI. ${ }^{[17]}$ In our study, at day 1 , the cutoff value $48.54 \mathrm{ng} / \mathrm{mL}$ had a sensitivity and specificity of 79.49 and 73.14, respectively, and the AUC of 0.82 (95\% CI, 0.75-0.87) for predicting AKI. Our study results are compatible to previous two studies.

In a prospective study conducted by Mishra et al. in patients undergoing cardiopulmonary bypass (CPB) surgery, they found that $\mathrm{UNGAL}$ concentrations $>50 \mathrm{ng} / \mathrm{mL}$ reliably predicted AKI in patients at only $2 \mathrm{~h}$ following CPB with $100 \%$ sensitivity and $98 \%$ specificity. ${ }^{[18]}$ Less optimistic results were reported among patients undergoing cardiac surgery; uNGAL levels were consistently higher at $1,3,18$, and $24 \mathrm{~h}$ postoperatively in patients who ultimately developed AKI with best cutoff of $213 \mathrm{ng} / \mathrm{mL}$ at $18 \mathrm{~h}$ postoperatively (with a sensitivity of $73 \%$ and a specificity of $78 \%){ }^{[19]}$

To predict the need for hemodialysis in septic AKI patients at day 1 , uNGAL at cutoff $45.54 \mathrm{ng} / \mathrm{mL}$ had a sensitivity and specifi city of 79.49 and 74.14 , respectively. On day 2 , uNGAL at cutoff value of $200.99 \mathrm{ng} / \mathrm{mL}$ had a sensitivity and specificity of 90.0 and 64.66, respectively, for predicting the need of hemodialysis. Our study result showed that on day1 at low cutoff value, uNGAL had good diagnostic accuracy, while on day 2 , sensitivity was improved but specificity decreased for prediction of renal replacement therapy (RRT). A study done by Fan et al. showed that the peak UNGAL were significantly higher in patients receiving hemodialysis compared with those not receiving hemodialysis (median, $456 \mathrm{ng} / \mathrm{mL}$ vs. $341 \mathrm{ng} / \mathrm{mL} ; P<0.0001$ ). At a cutoff level of $494 \mathrm{ng} / \mathrm{mL}$, the sensitivity and specificity of the peak UNGAL in predicting hemodialysis were $89 \%$ and $71 \%$, respectively. ${ }^{[20]}$ Another study done by Albeladi et al. showed that uNGAL on day 1 at cutoff level of $500 \mathrm{ng} / \mathrm{mL}$ had sensitivity $75 \%$, specificity $80 \%$ for RRT and $1000 \mathrm{ng} / \mathrm{mL}$ for day 2 levels (sensitivity $87.5 \%$; specificity $88 \%){ }^{[21]}$

As is evident from the analysis of the data collected, the sensitivity and specificity of UNGAL are relatively higher on the $1^{\text {st }}$ day itself in the patients of circulatory shock. The importance of this lies in the fact that measures can be adopted earlier to prevent the development or progression of AKI. Nephrotoxic medications can be avoided at an earlier stage, fluid therapy can be modified accordingly, and so on. The use 
of UNGAL in patients of circulatory shock at an earlier stage will not only help in foreseeing and preventing the possibility of AKI, but it will also reduce AKI-related complications, ICU stay, and mortality. This is especially useful in resource-poor country like India where there is an urgent need to detect and prevent complications and reduce economic burden and mortality from AKI. Finally, as discussed in previous sections, no one biomarker is ideal; however, given the excellent capacity of UNGAL to predict the development of AKI in circulatory shock, its use in critically ill patients for the same should be encouraged.

\section{Limitations}

The current study included a relatively small number of patients and therefore, our findings may be prone to type II errors. Validation is required in larger, varied population. We used serum creatinine level as a comparator to assess uNGAL performance and to define AKI, which is relatively insensitive.

\section{Conclusion}

A significant increase in UNGAL was observed in ICU patients following circulatory shock. UNGAL represents a good early predictor biomarker of AKI following circulatory shock and could predict the development of AKI 1-3 days earlier than serum creatinine. UNGAL at $1^{\text {st }}$ day following shock could predict further development of AKI. UNGAL may also be helpful in prediction for the need of RRT.

\section{Financial support and sponsorship}

Nil.

\section{Conflicts of interest}

There are no conflicts of interest.

\section{RefEREnCES}

1. de Mendonça A, Vincent JL, Suter PM, Moreno R, Dearden NM, Antonelli $\mathrm{M}$, et al. Acute renal failure in the ICU: Risk factors and outcome evaluated by the SOFA score. Intensive Care Med 2000;26:915-21.

2. Uchino S, Kellum JA, Bellomo R, Doig GS, Morimatsu H, Morgera S, et al. Acute renal failure in critically ill patients: A multinational, multicenter study. JAMA 2005;294:813-8.

3. Ympa YP, Sakr Y, Reinhart K, Vincent JL. Has mortality from acute renal failure decreased? A systematic review of the literature. Am J Med 2005;118:827-32.

4. Devarajan P. Emerging biomarkers of acute kidney injury. Contrib Nephrol 2007;156:203-12.

5. Haase M, Bellomo R, Devarajan P, Schlattmann P, Haase-Fielitz A, NGAL Meta-analysis Investigator Group, et al. Accuracy of neutrophil gelatinase-associated lipocalin (NGAL) in diagnosis and prognosis in acute kidney injury: A systematic review and meta-analysis. Am J Kidney Dis 2009;54:1012-24.

6. Soni SS, Cruz D, Bobek I, Chionh CY, Nalesso F, Lentini P, et al. NGAL: A biomarker of acute kidney injury and other systemic conditions. Int Urol Nephrol 2010;42:141-50.

7. Kjeldsen L, Cowland JB, Borregaard N. Human neutrophil gelatinase-associated lipocalin and homologous proteins in rat and mouse. Biochim Biophys Acta 2000;1482:272-83.

8. Cowland JB, Borregaard N. Molecular characterization and pattern of tissue expression of the gene for neutrophil gelatinase-associated lipocalin from humans. Genomics 1997;45:17-23.

9. von Elm E, Altman DG, Egger M, Pocock SJ, Gøtzsche PC, Vandenbroucke JP; STROBE Initiative. The Strengthening the Reporting of Observational Studies in Epidemiology (STROBE) statement: Guidelines for reporting observational studies. Ann Intern Med 2007;147:573-7.

10. Devarajan P, Mishra J, Supavekin S, Patterson LT, Steven Potter S. Gene expression in early ischemic renal injury: Clues towards pathogenesis, biomarker discovery, and novel therapeutics. Mol Genet Metab 2003;80:365-76.

11. Adiyanti SS, Loho T. Acute kidney injury (AKI) biomarker. Acta Med Indones 2012;44:246-55.

12. Devarajan P. Emerging biomarkers of acute kidney injury. Contrib Nephrol 2009;156:203-12.

13. Wagener G, Minhaz M, Mattis FA, Kim M, Emond JC, Lee HT, et al. Urinary neutrophil gelatinase-associated lipocalin as a marker of acute kidney injury after orthotopic liver transplantation. Nephrol Dial Transplant 2011;26:1717-23.

14. Mori K, Lee HT, Rapoport D, Drexler IR, Foster K, Yang J, et al. Endocytic delivery of lipocalin-siderophore-iron complex rescues the kidney from ischemia-reperfusion injury. J Clin Invest 2005;115:610-21.

15. Cruz DN, de Cal M, Garzotto F, Perazella MA, Lentini P, Corradi V, et al. Plasma neutrophil gelatinase-associated lipocalin is an early biomarker for acute kidney injury in an adult ICU population. Intensive Care Med 2010;36:444-51.

16. Constantin JM, Futier E, Perbet S, Roszyk L, Lautrette A, Gillart T, et al. Plasma neutrophil gelatinase-associated lipocalin is an early marker of acute kidney injury in adult critically ill patients: A prospective study. J Crit Care 2010;25:176.e1-6.

17. Fouda M, Sherif H, Shehata M, Ibrahim A. Early expression of urinary neutrophil gelatinase-associated lipocalin biomarker predicts acute kidney injury complicating circulatory shock. Egypt J Crit Care Med 2013;1:79-86.

18. Mishra J, Dent C, Tarabishi R, Mitsnefes MM, Ma Q, Kelly C, et al. Neutrophil gelatinase-associated lipocalin (NGAL) as a biomarker for acute renal injury after cardiac surgery. Lancet 2005;365:1231-8.

19. Wagener G, Jan M, Kim M, Mori K, Barasch JM, Sladen RN, et al. Association between increases in urinary neutrophil gelatinase-associated lipocalin and acute renal dysfunction after adult cardiac surgery. Anesthesiology 2006;105:485-91.

20. Fan H, Zhao Y, Zhu JH, Song FC. Urine neutrophil gelatinase-associated lipocalin in septic patients with and without acute kidney injury. Ren Fail 2014;36:1399-403.

21. Albeladi FI, Algethamy HM. Urinary neutrophil gelatinase-associated lipocalin as a predictor of acute kidney injury, severe kidney injury, and the need for renal replacement therapy in the Intensive Care Unit. Nephron Extra 2017;7:62-77. 